\title{
AFM-IR insights into the chemistry of interfacial tracking
}

DOI:

10.1039/c7ta06642b

Document Version

Accepted author manuscript

Link to publication record in Manchester Research Explorer

\section{Citation for published version (APA):}

Morsch, S., Bastidas, P. D., \& Rowland, S. M. (2017). AFM-IR insights into the chemistry of interfacial tracking. Journal of Materials Chemistry A, 5(46), 24508-24517. https://doi.org/10.1039/c7ta06642b

\section{Published in:}

Journal of Materials Chemistry A

\section{Citing this paper}

Please note that where the full-text provided on Manchester Research Explorer is the Author Accepted Manuscript or Proof version this may differ from the final Published version. If citing, it is advised that you check and use the publisher's definitive version.

\section{General rights}

Copyright and moral rights for the publications made accessible in the Research Explorer are retained by the authors and/or other copyright owners and it is a condition of accessing publications that users recognise and abide by the legal requirements associated with these rights.

\section{Takedown policy}

If you believe that this document breaches copyright please refer to the University of Manchester's Takedown Procedures [http://man.ac.uk/04Y6Bo] or contact uml.scholarlycommunications@manchester.ac.uk providing relevant details, so we can investigate your claim.

\section{OPEN ACCESS}




\title{
AFM-IR Insights into the Chemistry of Interfacial Tracking
}

\author{
Suzanne Morsch ${ }^{1}$, Pablo D. Bastidas ${ }^{2}$ and Simon M. Rowland ${ }^{2}$ \\ ${ }^{1}$ Corrosion and Protection Centre, School of Materials, The University of Manchester, Manchester, United \\ Kingdom \\ ${ }^{2}$ School of Electrical and Electronic Engineering, The University of Manchester, Manchester, United Kingdom
}

Abstract-Composite materials are increasingly used in high-voltage insulation, where interfacial aging is a major source of failure. Nonetheless, the mechanism underpinning polymeric degradation remains ill-defined. This is in part due to the highly localised and complex range of reactions induced by partial discharges. In this contribution, we first present a correlation between track propagation over time and the partial discharge magnitude in the region between a glassy epoxy amine resin and silicone rubber. We then use ATR-FTIR and the newly developed atomic force microscopy infrared (AFM-IR) technique to produce detailed nano-chemical maps of interfacial tracks and buried channels. Local infrared spectra reveal that oxidation of the epoxy resin, which has previously been associated with the formation of interfacial tracks and electrical trees when detected by conventional bulk FTIR, in fact occurs across the entire interface and is concentrated within the damaged channel regions. In contrast, for silicone rubber the bulk ATR-FTIR spectra remain essentially unchanged after electrical ageing, whereas local AFM-IR analysis reveals the development of Si-O-C bonds across the interface and C-O-C bonds within tracks. 


\section{Introduction}

Composite insulators are increasingly used in high-voltage transmission line applications due to their light weight and robust mechanical properties. These are typically comprised of a glassy pultruded core sheathed by a thermoset polymer covering shaped to provide weather-sheds (typically silicone rubber), terminated with metallic fittings, Scheme 1 . The sheds serve to increase the surface distance between metallic fittings, in order to reduce leakage currents and prevent flashover events.

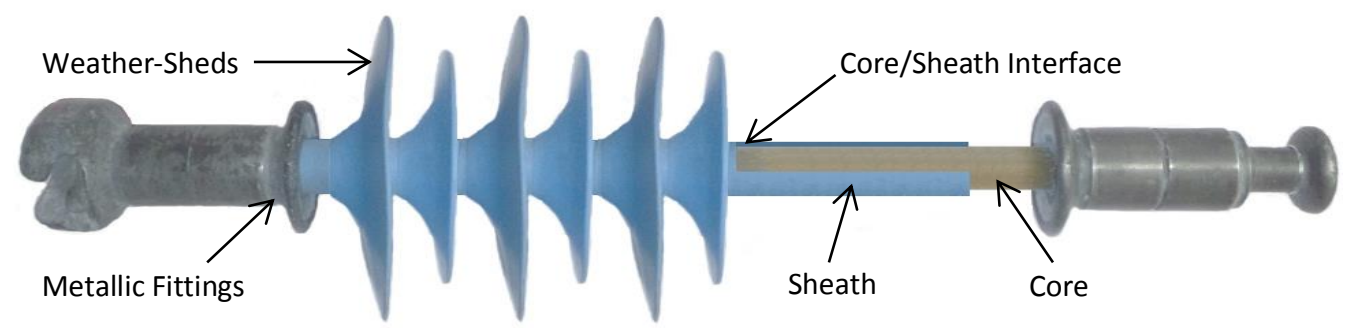

Scheme 1. Components of a medium voltage outdoor composite insulator with $300 \mathrm{~mm}$ separation between metal fittings (not to scale).

Issues concerning interfacial degradation have been reported for as long as this type of insulator has been used. Failure commonly occurs as a result of partial discharge events, initiated at microscopic defects such as in airgaps, free volume voids, and in the presence of contaminants. ${ }^{1,2,3}$ Polymer degradation then results from exposure to this discharge activity, i.e., localised electron and ion bombardment, thermal degradation and UV irradiation. Crucially, this discharge activity causes irreversible damage, via the development of characteristic channels along the pultruded rod/sheath interface. Ultimately, when such tracking occurs along a substantial length of the insulator, this can lead to its catastrophic failure through a flashover/power arc event, or else a sheath puncture, which can allow moisture penetration and stress corrosion cracking of the pultruded core.

An in-depth understanding of the chemical processes accompanying interfacial tracking (and electrical tree formation into the bulk) is therefore increasingly important for the development of insulator materials with enhanced resistance to breakdown..$^{4,5,6,7,8}$ Despite numerous efforts to characterise polymeric degradation by electrical discharge however, the mechanisms involved remain poorly defined. Previously, electron spin resonance (ESR) measurements have been used to demonstrate that radical species are active during electrical tree formation in bulk polyethylene. ${ }^{9}$ In addition, Raman spectroscopy has shown that short chain degradation products and conducting graphitic deposits are present in the 
dark channels which can be formed (carbonisation). ${ }^{10,11}$ Finally, infrared spectroscopy has been employed in a number of studies to show that polymer oxidation plays a key role in structural breakdown through exposure to partial discharge. ${ }^{12,13}$ In addition, Bolliger et al recently published a detailed study specifically on the chemistry of interfacial tracking (rather than electrical tree formation in bulk polymers), where mass spectroscopy data was used to show that a range of volatile short chain hydrocarbons are evolved from alkoxy radicals within epoxy and polyethylene specimens. ${ }^{14}$

A common feature of the aforementioned studies is the use of bulk analysis techniques, meaning that the results give only an overview of the chemical changes occurring within these complex systems. In contrast, the formation of electrical tree and surface tracking structures necessarily involves highly localised heterogeneous reactions. To overcome the limitations of bulk analysis, Hu et al recently reported the use of FTIR microspectroscopy to map electrical tree channels in polyethylene. ${ }^{15}$ High concentrations of oxygenated functional groups $(\mathrm{C}=\mathrm{O}, \mathrm{C}-\mathrm{OH}$ and $\mathrm{C}-\mathrm{O}-\mathrm{C})$ were found to be present in the channels by infrared mapping. However, whilst this methodology resolved differences between the channels and intact polymer regions, resolution was limited to a few pixels per channel width. This is unsurprising, since infrared microspectroscopy techniques conventionally suffer diffraction-limited resolution associated with the wavelength of light in the mid-IR spectral range. In contrast, the newly developed atomic force microscopy infrared spectroscopy (AFM-IR) approach circumvents these limitations by using an AFM probe to detect local photothermal expansion in response to infrared excitation, routinely providing local spectra and detailed infrared maps with lateral resolution better than $50 \mathrm{~nm} .{ }^{16}$ This approach has previously been applied to probe the interfacial chemistry of carbon fibre/epoxy composites, ${ }^{17}$ and to map chemical heterogeneity and water transport within epoxy-phenolic resins. ${ }^{18,19,20}$ In this study, we apply AFM-IR to investigate electrical aging for the first time, specifically to examine the local chemistry of interfacial tracking between an epoxy resin and silicone rubber. 


\section{Experimental}

\section{Sample Preparation and Aging}

Epoxy resins were prepared as follows: Araldite-LY5052 and Aradur-HY5052 hardener (Huntsman) were mixed 100:38 by weight, then degassed in a vacuum chamber for 50 minutes, and cured in a $5 \mathrm{~mm}$ deep, $150 \mathrm{~mm} \times 50 \mathrm{~mm}$ PTFE frame placed over a polycarbonate sheet. Epoxy plaques readily demoulded once cured (after 24 hours under ambient conditions and 4 hours post-cure at $100{ }^{\circ} \mathrm{C}$ ) and were stored under ambient conditions prior to testing. Unfilled high temperature vulcanized silicone rubber (Polymax) was used as received. Immediately before assembly, the silicone rubber and stainless steel wire electrode ( $45 \mu \mathrm{m}$ diameter) were cleaned with propanol, whilst the epoxy resin plaque was rinsed with deionised water. Components were dried with warm air for 2 minutes, then the wire was placed between the two dielectrics, which were pressed together manually until all observable trapped air at the interface was removed, before being compressed to a fixed pressure of $60 \mathrm{kPa}$. The tip of the wire was bent into a circular shape of $1.2 \mathrm{~mm}$ diameter in order to provide a reproducible local electrical field enhancement and initiate partial discharge activity, Scheme 2. Samples were supported on a glass plate, so that a camera (Canon EOS-1100D) could capture images of degradation and light emission from below. Ceramic bricks $\left(\varepsilon_{\mathrm{r}}=6-8\right)$ were used as dead weights to maintain the mechanical pressure on samples at $60 \mathrm{kPa}$.

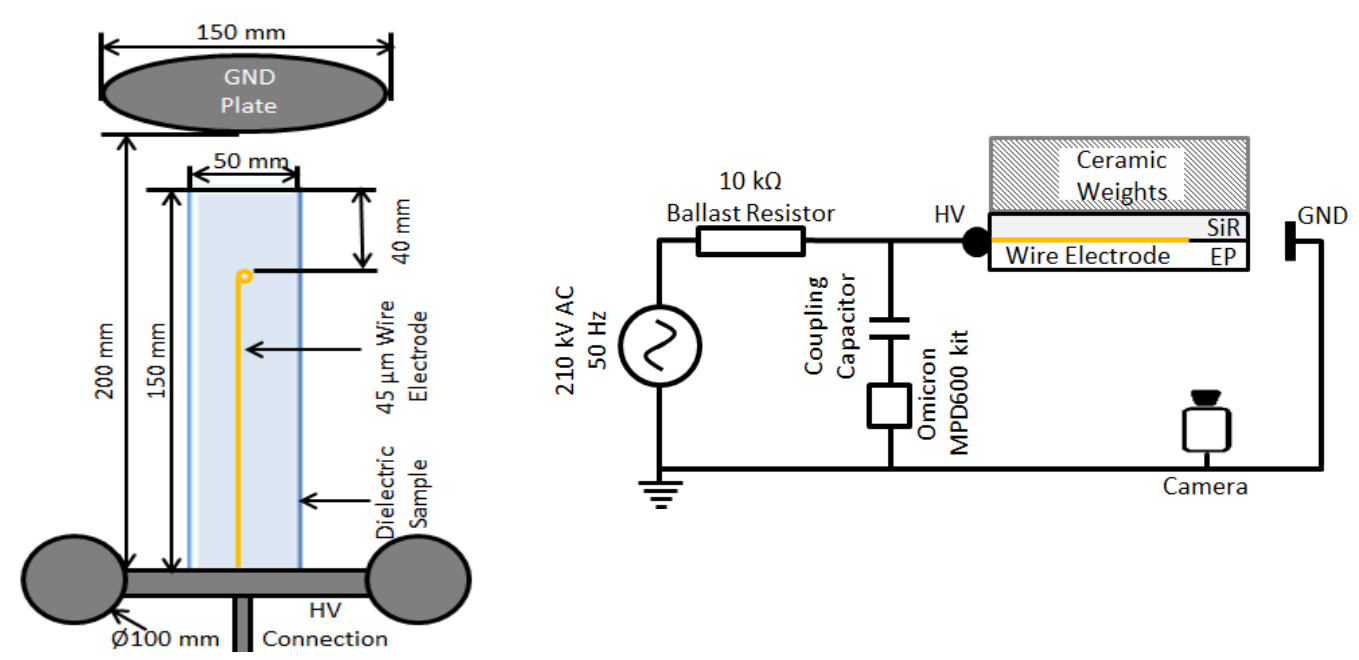

Scheme 2. Top view and circuit diagram of the experimental set-up used to test interfacial degradation.

An Omicron MPD600 measurement system was used to monitor partial discharge magnitudes and the partial discharge inception voltage, whilst an optical camera was used to 
monitor visible degradation. The length and width of interfacial tracked regions were assessed using camera images obtained at 30 minute intervals, using digital imaging software. An AC voltage of $42 \mathrm{kV}$ RMS was applied to the HV connection for 1020 minutes or 6000 minutes (to produce sample $A$ and sample $B$ respectively).

Prior to chemical characterisation, the epoxy and silicone plaques were separated to expose the degraded interface. Vibrational spectroscopy techniques were then used to interrogate functional group chemistry at the exposed interface.

\section{ATR-FTIR}

Bulk infrared spectra were obtained from 64 co-averages collected in ATR mode using an FTIR spectrometer (Nicolet 5700 spectrometer, Thermo Electron Corp.) operating at $4 \mathrm{~cm}^{-1}$ resolution across the $500-4000 \mathrm{~cm}^{-1}$ range with a diamond internal reflection element.

\section{AFM-IR}

Nanoscale infrared analysis (AFM-IR) was performed on a NanolR2 system (Anasys Instruments) operating with top-down illumination. During AFM-IR analysis, specimens were illuminated by a pulsed, tuneable infrared source (optical parametric oscillator, with $10 \mathrm{~ns}$ pulses at a repetition rate of $1 \mathrm{KHz}$, with an approximate beam spot size of $30 \mu \mathrm{m}$ ). Subdiffraction limit resolution was achieved by monitoring the deflection of an AFM probe in contact with the surface. This results from rapid transient thermal expansion of the material in contact with the probe tip in response to infrared absorbance, Scheme $3{ }^{16}$ The recorded AFM-IR signal is the amplitude of induced AFM probe oscillation, obtained after fast Fourier transform. This has previously been shown to correlate to infrared absorbance measured using conventional macroscopic FTIR. ${ }^{21}$ Since the IR pulse (10 ns duration), thermal expansion, and damping down of the induced oscillation occur on a shorter timescale than the feedback electronics of the AFM, simultaneous contact-mode topographical measurement and infrared mapping may also be performed at a given wavelength. ${ }^{22,23,24,25}$ For the present study, AFM-IR images were collected in contact mode at a scan rate of 0.04 $\mathrm{Hz}$ using a gold-coated silicon nitride probe $(0.07-0.4 \mathrm{~N} / \mathrm{m}$ spring constant, $13 \pm 4 \mathrm{kHz}$ resonant frequency, Anasys Instruments). The amplitudes of infrared induced oscillations were recorded at a given wavelength using 32 co-averages for 600 points per 300 scan lines. Spectra were obtained using 1024 co-averages for each data point. 


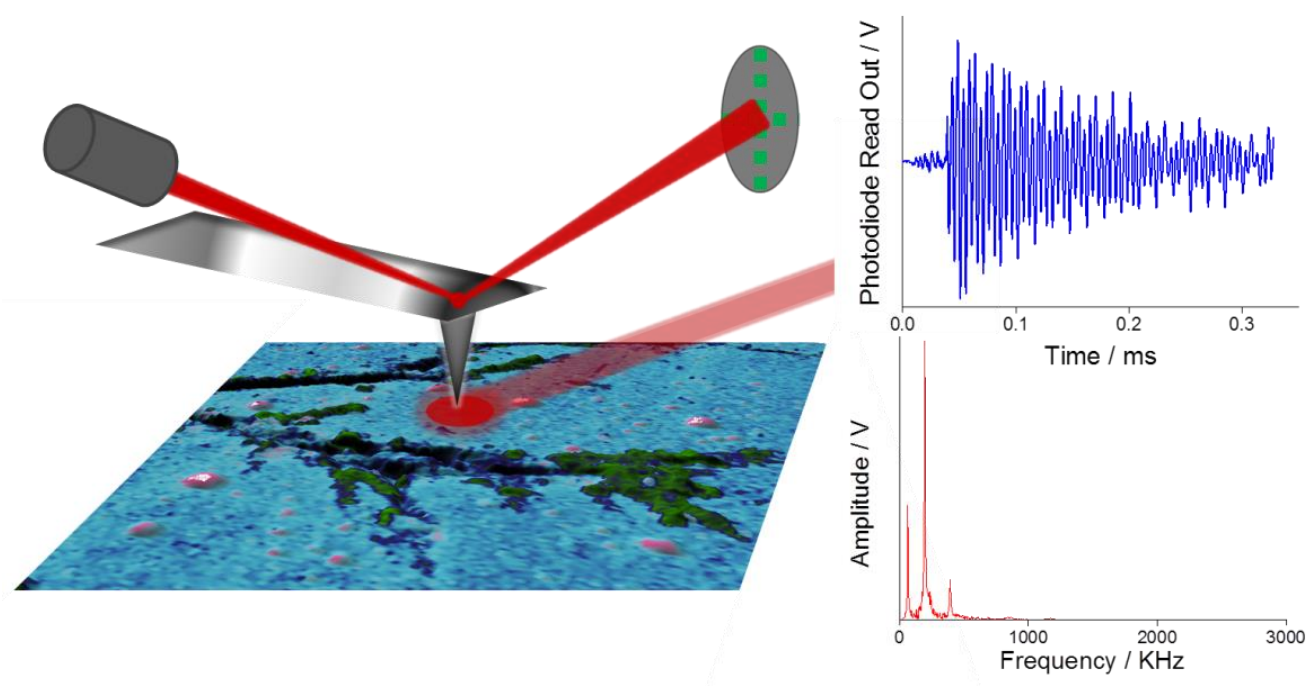

Scheme 3. The AFM-IR experiment with top-down illumination. The IR source is pulsed, inducing rapid thermal expansion of the sample, which is detected by deflection of the AFM probe cantilever. The recorded AFM-IR signal corresponds to the amplitude following a fast Fourier transform of the deflection signal. 


\section{Results and Discussion}

\section{Partial Discharge Development}

Figure 1 shows optical microscopy images of the two epoxy samples electrically stressed for different periods of time. After 1020 minutes (sample A), fine white/yellow channels were observed to spread in predominately two-dimensional treeing patterns. When discharge activity was allowed to continue for 6000 minutes, (sample B), the channels widened and darkened in colour.



(a)



(b)

Figure 1. Optical microscopy images showing the interfacial channels and the structure of the branches developed in the epoxy resin after (a) 1020 minutes of electrical stress and (b) 6000 minutes of electrical stress.

Optical inspection of interfacial tracks indicated a similar manner of track growth occurred during both tests (Figure 1), and reproducibility was further indicated by the inception voltages, which were found to be $4.4 \mathrm{kV}$ in both cases, with partial discharge magnitudes of $10.8 \mathrm{pC}$ and 12.0 $\mathrm{pC}$ for test $\mathrm{A}$ and test $\mathrm{B}$ respectively. Furthermore, comparison of the visibly tracked regions after 1020 minutes electrical stress confirmed similar tracking rates in both tests; the dimensions of tracked regions were $22.5 \mathrm{~mm} \times 15.4 \mathrm{~mm}$ for sample $A$, and $23.2 \mathrm{~mm} \times 17.0 \mathrm{~mm}$ for sample $B$. For sample B, this represents approximately $85 \%$ of the visibly damaged area produced after 6000 minutes electrical stress, indicating that the growth of new channels slows over the duration of the test.

To confirm this, Figure 2 shows a comparison of the maximum partial discharge magnitude per second, alongside dimensions of the visibly tracked interfacial region of Sample B as a function of test time. Whilst some channels do penetrate into the bulk epoxy, growth of the visibly damaged 
region primarily occurred via tracking along the interface, so the length and width of this region reflects the extent of damage well. The recorded partial discharge magnitudes are generally consistent with expectations of tracking activity; however track growth slowed significantly towards the end of the test, with the visibly degraded region extending only $120 \mu \mathrm{m}$ further in length and $110 \mu \mathrm{m}$ in width during the final 8 hours. This reduction in growth rate is attributed to tracks growing away from the local field enhancement caused by the electrode geometry. In the configuration used, the planar ground electrode is distant from the hook electrode, so that the field does not increase significantly as the track grows, i.e., tracks were growing in an effectively constant field. ${ }^{26}$ This indicates that the black deposits observed to develop adjacent to the hook electrode (Figure 1) do not significantly enhance the discharge activity as the generation of conducting carbon species might be expected to.

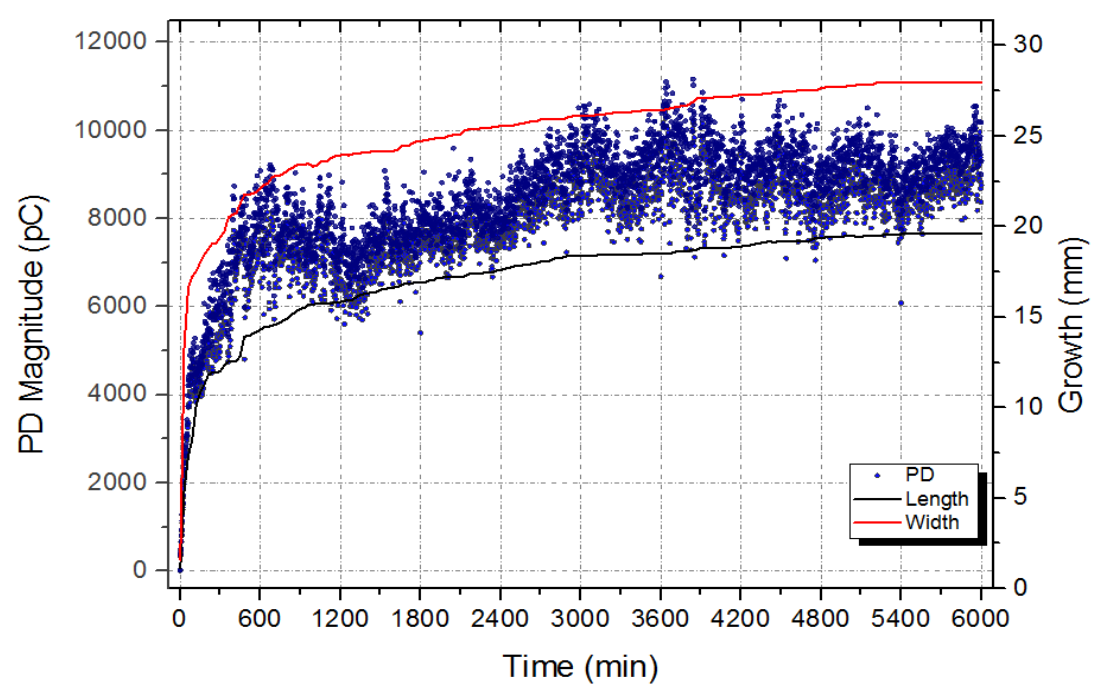

Figure 2. Partial discharge (PD) magnitudes and the dimensions of visible interfacial channel growth as a function of time during test $B$.

\section{Epoxy Resin FTIR Analysis}

In order to establish whether oxidation of the epoxy resin occurred during interfacial tracking and electrical tree formation, conventional ATR-FTIR analysis was performed, Figure 3. Characteristic epoxy-amine infrared peaks were identified prior to the interfacial tracking experiment, and are summarised in Table 1. After 1020 minutes of electrical aging (corresponding to white channels spread across the interface), only minor spectral changes were identified; the intensity of the hydroxyl $\mathrm{O}-\mathrm{H}$ region (centred around $3300 \mathrm{~cm}^{-1}$ ) increased relative to that of characteristic $\mathrm{C}-\mathrm{H}$ stretch absorbance peaks at $2920 \mathrm{~cm}^{-1}$ and $2849 \mathrm{~cm}^{-1}$, indicating some degree of oxidation. In 
addition, the appearance of a broad band at $1660 \mathrm{~cm}^{-1}$ was observed, attributable to the $\mathrm{C}=\mathrm{C}$ stretch of alkene species, Figure 3b. Prolonged electrical stress (after 6000 minutes, test B) was found to result in further oxidation; characterised by increased hydroxyl absorbance, the introduction of a broad ester carbonyl band and a broad, intense peak around $1336 \mathrm{~cm}^{-1}$, associated with overlapping nitrates and nitrite $\mathrm{N}-\mathrm{O}$ stretches, Figure $3 \mathrm{c}^{27,28}$

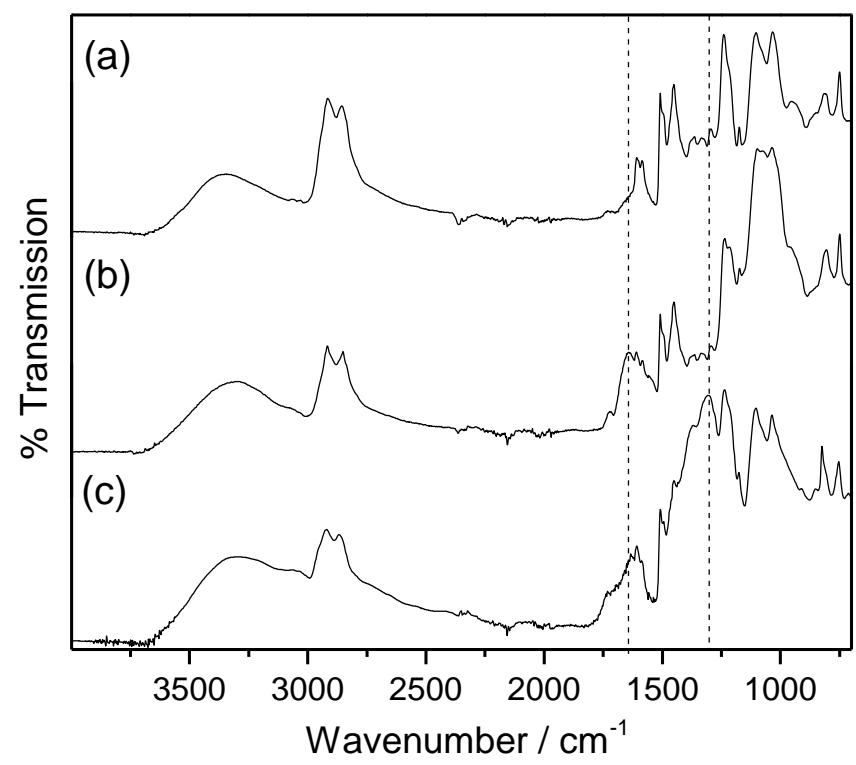

Figure 3. ATR mode FTIR spectra of the epoxy samples collected (a) before interfacial tracking experiment (b) Sample A after exposure to partial discharge for 1020 min and (c) Sample B after exposure to partial discharge for $6000 \mathrm{~min}$.

The appearance of hydroxyl and carbonyl absorbance peaks is to be expected after electrical aging, since these groups are commonly formed during thermal or photo aging of epoxy resins (i.e., degradation mechanisms active during exposure to partial discharge conditions). ${ }^{29,30}$ The generation of these species has previously been identified by infrared analysis within epoxy resin and polyethylene specimens after electrical treeing, ${ }^{12,13,31}$ and furthermore, the introduction of carbonyl and hydroxyl bonds is consistent the auto-oxidation of polymers via alkoxy radical intermediates. ${ }^{14}$ This is considered to be a key reaction pathway active during interfacial tracking, where the formation of alkoxy radicals is induced by peroxide radical attack. The appearance of $\mathrm{N}-\mathrm{O}$ bonds has also previously been reported in the case of electrically aged epoxy-amine resins; indeed the infrared spectrum recorded after 6000 minutes (test B) corresponds remarkably well with that reported for an epoxy amine resin exposed to partial discharge in air for 50 hours. $^{32}$ In that study, 
Hepburn et al. found that oxygenation and the formation of $\mathrm{N}-\mathrm{O}$ bonds occurred during exposure to partial discharge under ambient humidity, but these characteristic degradation peaks were absent when samples were aged by partial discharge in dry air. This indicates that in the present study, sufficient moisture remained at the interface for degradation to occur in a similar manner to partial discharge under ambient humidity, and this is unsurprising, given that amorphous glassy epoxy resins are well known to absorb a nominal amount of moisture under ambient conditions. ${ }^{33}$ The introduction of $\mathrm{N}-\mathrm{O}$ bonds may also be the result of bombardment with excited species present in corona discharge (e.g., $\mathrm{NO}^{+}\left(\mathrm{H}_{2} \mathrm{O}\right)_{n}, \mathrm{NO}_{2}^{+}\left(\mathrm{H}_{2} \mathrm{O}\right)_{n}$, ions ${ }^{34,35}$ ), however given that these peaks rarely appear in reports of electrical treeing for polyethylene samples (and when this has been reported, the peaks were much less intense ${ }^{36}$ ), direct oxidation of the amine linkages in the network seems more probable.

Table 1: Vibrational spectroscopy peak positions and assignments for epoxy resin samples.

\begin{tabular}{c|c} 
Wavenumber & Peak Assignment \\
\hline $1039 \mathrm{~cm}^{-1}$ & C-O deformations, para-substituted CH bending \\
$1104 \mathrm{~cm}^{-1}$ & Secondary hydroxyl O-H asymmetric deformation \\
$1253 \mathrm{~cm}^{-1}$ & Aryl/acid/ester C-O stretch \\
$1306 \mathrm{~cm}^{-1}$ & $\mathrm{~N}$-O stretch in nitrates / nitrites \\
- & $\left(\mathrm{CH}_{2}\right)_{n}$ in-phase twist \\
$1385 \mathrm{~cm}^{-1}$ & $\mathrm{CH}_{2}$ wag \\
$1453 \mathrm{~cm}^{-1}$ & $\mathrm{CH}_{2}$ scissoring / aromatic semicircle stretch \\
$1505 \mathrm{~cm}^{-1}$ & Aromatic ring semicircle stretch \\
$1511 \mathrm{~cm}^{-1}$ & Aromatic ring quadrant stretch \\
$1589 \mathrm{~cm}^{-1}$ & Aromatic ring quadrant stretch and $\mathrm{NH}_{2}$ \\
$1660 \mathrm{~cm}^{-1}$ & deformation \\
$1752 \mathrm{~cm}^{-1}$ & Alkene C=C stretch \\
$2849 \mathrm{~cm}^{-1}$ & Ester C=O stretch \\
$2920 \mathrm{~cm}^{-1}$ & $V_{s} \mathrm{CH}_{2}$ stretch \\
$3300 \mathrm{~cm}^{-1}$ & $V_{\text {as }} \mathrm{CH}_{2}$ stretch \\
& Hydroxyl O-H stretch
\end{tabular}




\section{Epoxy AFM-IR}

AFM-IR was employed to examine the local chemistry of interfacial tracking in detail. Using AFM-IR, the effective sampling volume (corresponding to material in contact with the AFM probe) is reduced, yielding enhanced lateral and surface resolution in comparison to ATR-FTIR (where the sampling space encompasses the bulk intact polymer, sub-surface tree channels and interfacial tracks). This allowed selective inspection of the fine channels located at the periphery of tracking structures, in order to identify chemical changes accompanying early stages of polymer degradation. Local infrared spectra were obtained by positioning the AFM-IR probe in contact the surface of specimens and stepping the pulsed radiation incident on the probe tip through the mid-IR fingerprint range $\left(900 \mathrm{~cm}^{-1}-1800 \mathrm{~cm}^{-1}\right)$. The amplitude of probe oscillations induced by thermal expansion of the sample in contact with the probe (IR amplitude) was then monitored and plotted at various probe positions, Figure 4.

Local AFM-IR spectra of the as-prepared epoxy resin (obtained prior to electrical aging) displayed peak positions in good agreement with those obtained using conventional ATR-FTIR, Figure 4a. In damaged regions after electrical stress however, significant differences arose (Figures $4 \mathrm{~b}$ and $4 \mathrm{c})$. After 1020 minutes exposure to partial discharge, the most striking difference is the detection of absorbance at $1752 \mathrm{~cm}^{-1}$ at all points measured using AFM-IR, indicating that oxidation occurred across the region. In addition, comparatively enhanced absorbance was detected at 1284 $\mathrm{cm}^{-1}$ and $1306 \mathrm{~cm}^{-1}$, and was attributed to the early formation of nitrates and nitrites. After normalisation to the aromatic $1505 \mathrm{~cm}^{-1}$ band, the relative intensity of absorbance associated with $\mathrm{N}-\mathrm{O}$ bonds was, however, found to vary very little across the surface, rather than being concentrated within channels. In contrast, the relative intensity of ester carbonyl and carboxylic acid/alkene $\mathrm{C}=\mathrm{C}$ absorbance peaks varied dramatically depending on the probe tip location. Accordingly, the normalised spectra could be sub-divided into three distinct regimes: spectra taken from locations of seemingly intact resin showed some evidence of $\mathrm{C}=\mathrm{O}$ and $\mathrm{N}-\mathrm{O}$ bond formation (red spectra, Figure $4 \mathrm{~b}$ ), whilst spectra taken at tip locations corresponding to buried channels (visible as slightly raised tracks in the height image, presumably due to the expansion of gas in channels during partial discharge) displayed comparatively enhanced absorbance at $1752 \mathrm{~cm}^{-1},(\mathrm{C}=\mathrm{O}$ stretch) and at $1248 \mathrm{~cm}^{-1}$ (C-O stretch), indicating that a high concentration of ester groups exists within the channels (blue spectra, Figure 4b). Lastly, spectra obtained from regions peripheral to the channels displayed relatively high absorbance at $1660 \mathrm{~cm}^{-1}$ (unsaturated $\mathrm{C}=\mathrm{C}$ stretch) and at $1080 \mathrm{~cm}^{-1}$, (hydroxyl asymmetric deformation) (green spectra, Figure 4b). 
This spatial distribution of generated carbonyl, hydroxyl and alkene groups was further confirmed by nanoscale infrared mapping, Figure 5. Infrared amplitude signals corresponding to ester groups (at $1248 \mathrm{~cm}^{-1}$ and $1748 \mathrm{~cm}^{-1}$, Figures $5 \mathrm{c}$ and $5 \mathrm{f}$ respectively) were indeed found to be most intense over the channels, and relatively depleted in regions just outside these channels (e.g., locations marked by arrows). This coincided with enhanced amplitude signals at wavelengths associated with unsaturated bonds and hydroxyl groups $\left(1660 \mathrm{~cm}^{-1}\right.$ and $1080 \mathrm{~cm}^{-1}$ respectively, Figures $5 \mathrm{~b}$ and $5 \mathrm{e})$. In contrast, absorbance at $1336 \mathrm{~cm}^{-1}$ and $1456 \mathrm{~cm}^{-1}$ was found to vary little across the surface, in accordance with local spectra. Since AFM-IR measurements detect infrared absorbance indirectly via thermal expansion, some correlation to height features might be expected (as a consequence of varied tip-sample contact area, or a lower thermal expansion coefficient of the damaged resin). In light of this, a further control scan was performed at $1505 \mathrm{~cm}^{-1}$, corresponding to aromatic groups. This infrared map was comparatively featureless, demonstrating that the infrared amplitude signals observed do indeed correspond to chemical differences.

Several conclusions about the interfacial degradation process can be drawn from the AFM-IR data for sample A (1020 minutes aging). Firstly, the results clearly indicate that the polymer degradation process detected using conventional infrared spectroscopy is not limited to visible tracks formed during partial discharge. The presence of $\mathrm{C}=\mathrm{O}$ and $\mathrm{N}-\mathrm{O}$ absorbance in all regions probed using AFM-IR indicate that seemingly intact regions undergo some degree of oxidative decay during electrical stressing. Secondly, since the concentration of ester groups is highest inside channels (and only detected during later stages of aging by ATR-FTIR spectroscopy) it can be surmised that esterification occurs during later stages of oxidative degradation. On the other hand, the formation of hydroxyl and alkene groups in regions around tracks indicates that these species are a precursor to visible degradation in the form of widening channels. In addition, since these peaks are the dominant change detected by ATR-FTIR at this stage (where sampling depth is expected to be greater), it seems likely that these species also correspond to the dominant chemical processes occurring as electrical tree channels extend into the bulk. 

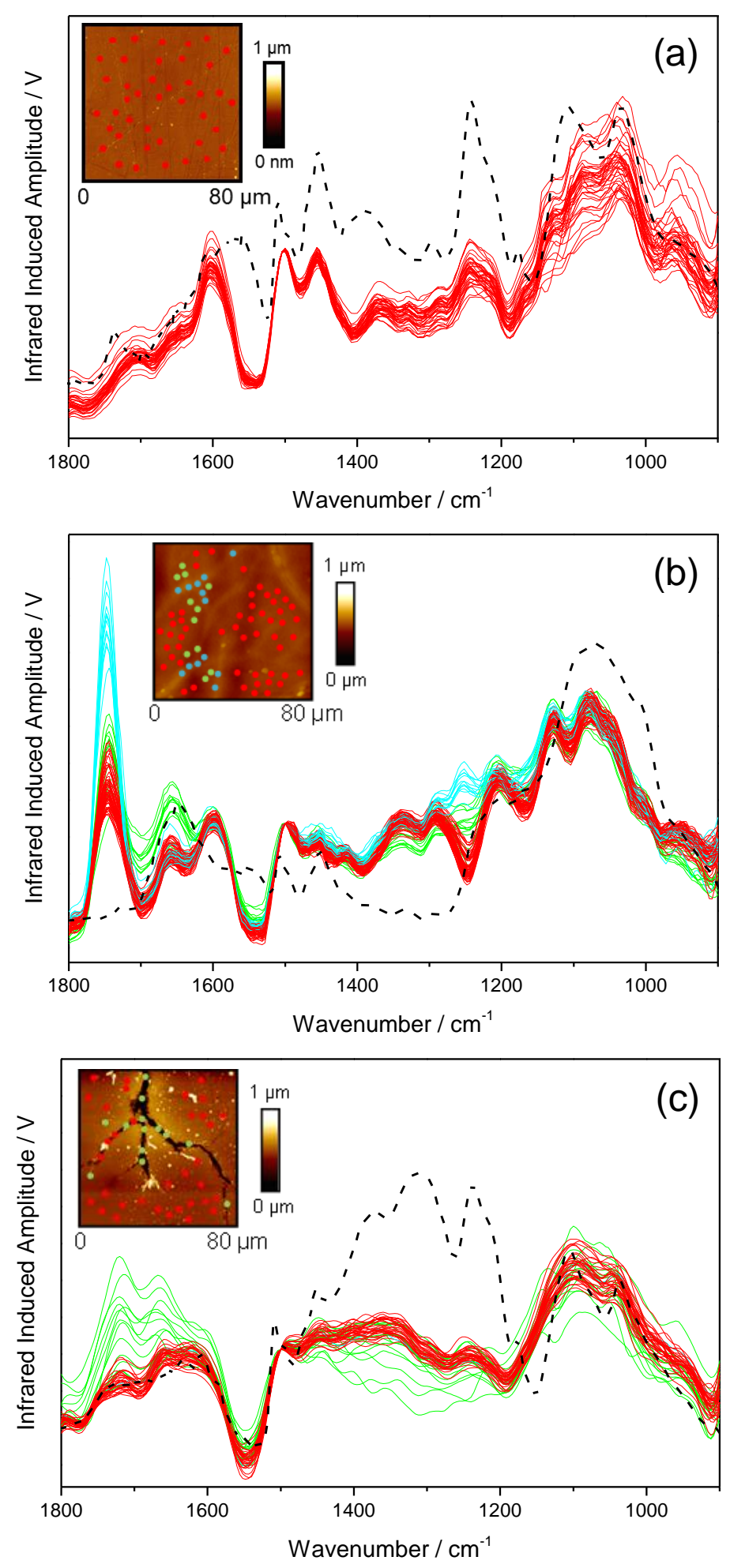

Figure 4. AFM-IR spectra corresponding to tip locations indicated by markers on the contact mode height image (inset) of epoxy resins (a) before and (b) after 1020 minutes electrical stress for Sample A (stage 1), and (c) after 6000 minutes electrical stress for Sample B (stage 2). AFM-IR spectra are normalised to the $1505 \mathrm{~cm}^{-1}$ peak. The corresponding bulk ATR-FTIR spectrum is indicated by the black dashed line. 

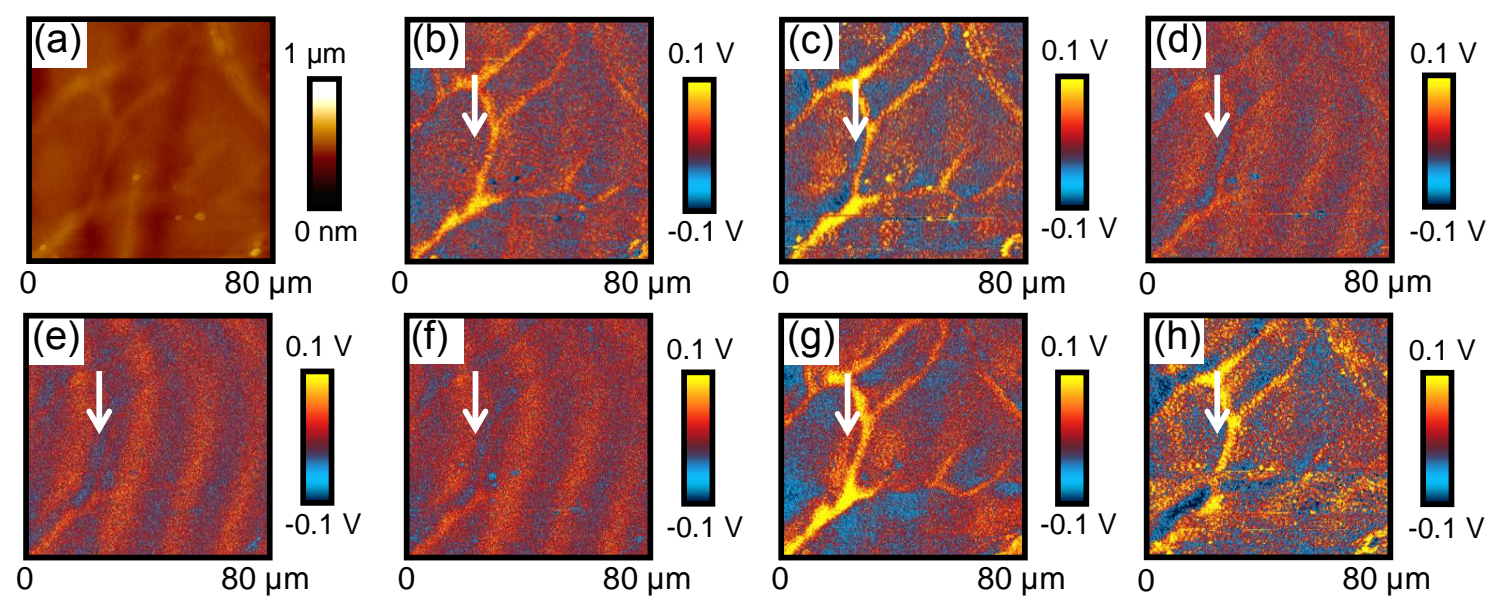

Figure 5. $80 \mu \mathrm{m} \times 80 \mu \mathrm{m}$ AFM-IR images of the epoxy resin surface of Sample A after 1020 minutes electrical aging: (a) contact mode height image, and maps of the amplitude signal induced by pulsed infrared illumination at (b) $1080 \mathrm{~cm}^{-1}$; (c) $1248 \mathrm{~cm}^{-1}$; (d) $1336 \mathrm{~cm}^{-1}$; (e) $1456 \mathrm{~cm}^{-1}$; (f) $1505 \mathrm{~cm}^{-1}$; (g) $1660 \mathrm{~cm}^{-1}$, and (h) $1752 \mathrm{~cm}^{-1}$.

AFM-IR analysis was also performed around exposed interfacial tracks found the periphery of the damaged region produced after growth had slowed down (i.e., after prolonged electrical stress for 6000 minutes, Sample B), Figure 4c. Peaks observed in the localised spectra once again differed significantly to those measured using bulk ATR-FTIR, displaying relatively enhanced carbonyl absorbance (although this is far less pronounced than in the specimen aged for 1020 mins, Sample A), and reduced absorbance across the $1200 \mathrm{~cm}^{-1}-1450 \mathrm{~cm}^{-1}$ region associated with $\mathrm{C}-\mathrm{H}, \mathrm{C}-\mathrm{O}$ and N$O$ bonds. It is also noteworthy that the overall infrared amplitude signal was attenuated in comparison to Sample A, and absorbance peaks generally became broad and ill-defined across the surface. This corresponds to a loss of functionality, consistent with the breakdown in structure and release of volatiles associated with extensive polymer degradation. Moreover, during infrared mapping relatively low signals were detected within surface tracks at all the wavenumbers scanned, further indicating breakdown, in keeping with the eventual degradation to dark deposits of amorphous carbon inside tracks, Figure 6.

To directly visualise relative differences in absorbance, ratio images were generated by division of the amplitude signal by the amplitude detected at $1505 \mathrm{~cm}^{-1}$, (corresponding to the aromatic rings, akin to the normalisation procedure used for local spectra), Figure 7. Ratio images generated using $1752 \mathrm{~cm}^{-1} / 1505 \mathrm{~cm}^{-1}$ amplitude maps confirmed that ester carbonyl absorbance was enhanced (relative to aromatic groups) within the tracks, whereas images generated $1660 \mathrm{~cm}^{-1} /$ $1505 \mathrm{~cm}^{-1}$ amplitude maps demonstrated that alkene absorbance was relatively high around the tracks, consistent with the results obtained for buried channels produced in Sample A, Figure 5. All 
other wavenumbers scanned showed lower absorbance relative to the aromatic groups, indicating that $\mathrm{C}-\mathrm{O}, \mathrm{O}-\mathrm{H}$ and $\mathrm{N}-\mathrm{O}$ bonds are attacked whilst aromatic rings remain intact.
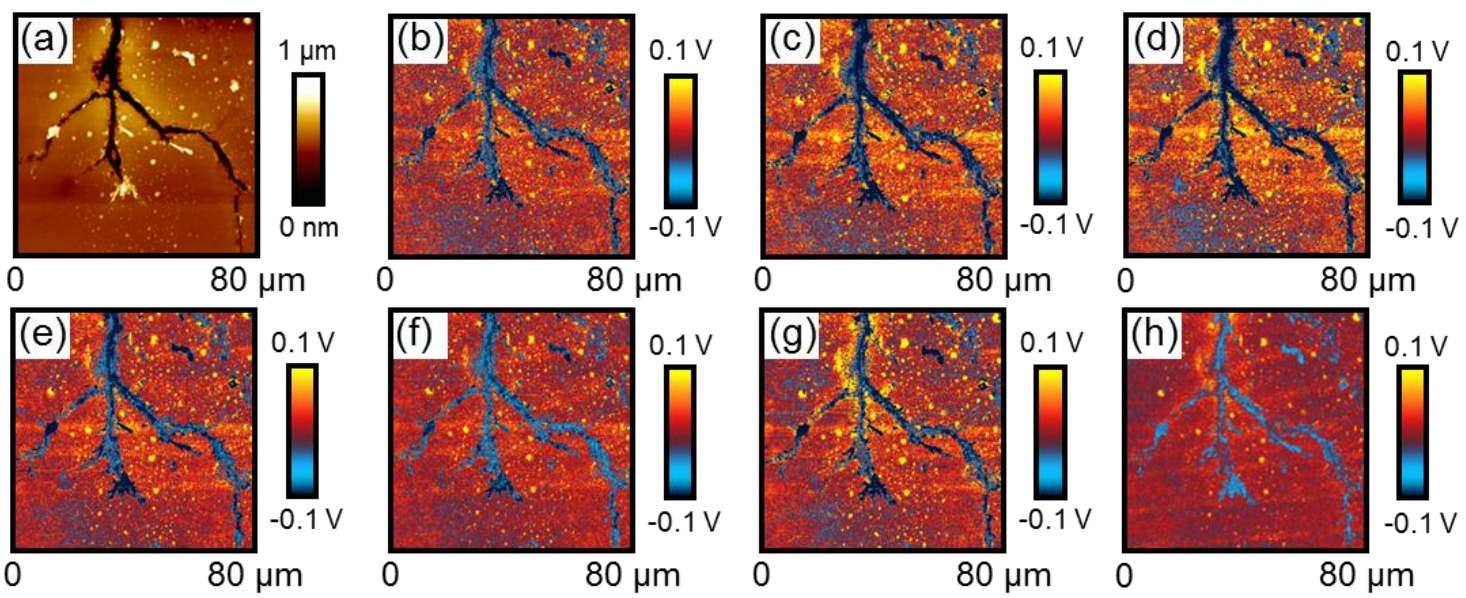

Figure 6. $80 \mu \mathrm{m} \times 80 \mu \mathrm{m}$ AFM-IR images of the epoxy resin surface of Sample B after 6000 minutes electrical aging: (a) contact mode height image and maps of the amplitude signal induced by pulsed infrared illumination at (b) $1080 \mathrm{~cm}^{-1}$; (c) $1248 \mathrm{~cm}^{-1}$; (d) $1336 \mathrm{~cm}^{-1}$; (e) $1456 \mathrm{~cm}^{-1}$; (f) $1505 \mathrm{~cm}^{-1}$; (g) $1660 \mathrm{~cm}^{-1}$, and (h) $1752 \mathrm{~cm}^{-1}$.
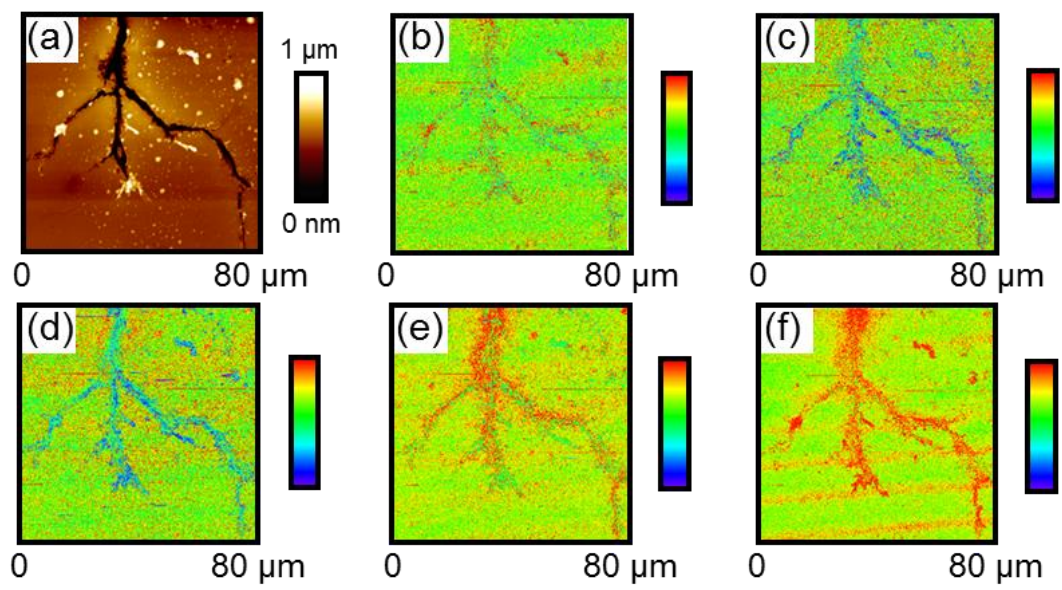

Figure 7. $80 \mu \mathrm{m} \times 80 \mu \mathrm{m}$ AFM-IR images of the epoxy resin surface of Sample B after 6000 minutes electrical aging: (a) contact mode height image, and ratio maps generated from infrared amplitude maps gathered at: (b) $1080 \mathrm{~cm}^{-1} / 1505 \mathrm{~cm}^{-1}$; (c) $1248 \mathrm{~cm}^{-1} / 1505 \mathrm{~cm}^{-1}$; (d) $1336 \mathrm{~cm}^{-1} / 1505 \mathrm{~cm}^{-1}$; (e) $1660 \mathrm{~cm}^{-1} / 1505 \mathrm{~cm}^{-1}$, and (f) $1752 \mathrm{~cm}^{-1} / 1505 \mathrm{~cm}^{-1}$.

The appearance of a broad absorbance around $1660 \mathrm{~cm}^{-1}$ is attributed to the formation of alkene groups, since the generation of low molecular weight unsaturated species has been confirmed using mass spectroscopy after interfacial tracking on an epoxy resin. ${ }^{14}$ Two potential 
mechanisms for alkene formation have been proposed; direct hydrogen abstraction from alkyl radicals, or a Norrish type II mechanism, involving hydrogen abstraction from an excited carbonyl species (via a diradical intermediate) to produce an alkene and ketone. Bolliger et al previously concluded that the former is more likely, since the quantum yield of a diradical intermediate is expected to be low. ${ }^{14}$ The spatial distribution of infrared absorbance in the present study supports this conclusion, since locally enhanced carbonyl absorbance is not found to coincide with regions displaying high signals at $1660 \mathrm{~cm}^{-1}$ and no ketone peak (expected around $1710 \mathrm{~cm}^{-1}$ ) was detected.

Finally, to confirm that electrical stress generates chemical changes across the interface rather than being confined to channels, a cross-section of the epoxy sample exposed to 6000 minutes of electrical stress was produced by microtome and examined using AFM-IR. Due to the roughness of the surface produced, ratio maps were again produced relative to the amplitude at $1505 \mathrm{~cm}^{-1}$. Clear differences in absorbance were detected, where the intensity of carbonyl, hydroxyl, alkene and nitrate/nitrite absorbance increased towards the interface. Interestingly, absorbance associated with $\mathrm{C}-\mathrm{O}$ and $\mathrm{O}-\mathrm{H}$ groups were found to be most intense within the first few microns, whereas the absorbance at $1336 \mathrm{~cm}^{-1}$ associated with nitrates, alkenes at $1660 \mathrm{~cm}^{-1}$ and carbonyl bands at 1752 $\mathrm{cm}^{-1}$ were more intense at greater depths, Figure 8. This could imply that the $\mathrm{C}=\mathrm{C}, \mathrm{C}=\mathrm{O}$ and $\mathrm{N}-\mathrm{O}$ bonds formed during oxidation are eliminated from the interface with prolonged oxidative decay (in keeping with the relatively low absorbance of these bands in the surface sensitive AFM-IR spectra of Sample B when compared to Sample A). However, further investigation is required, since tip effects at the edge of these unsupported specimens, and the migration of silicone rubber degradation products cannot be ruled out.
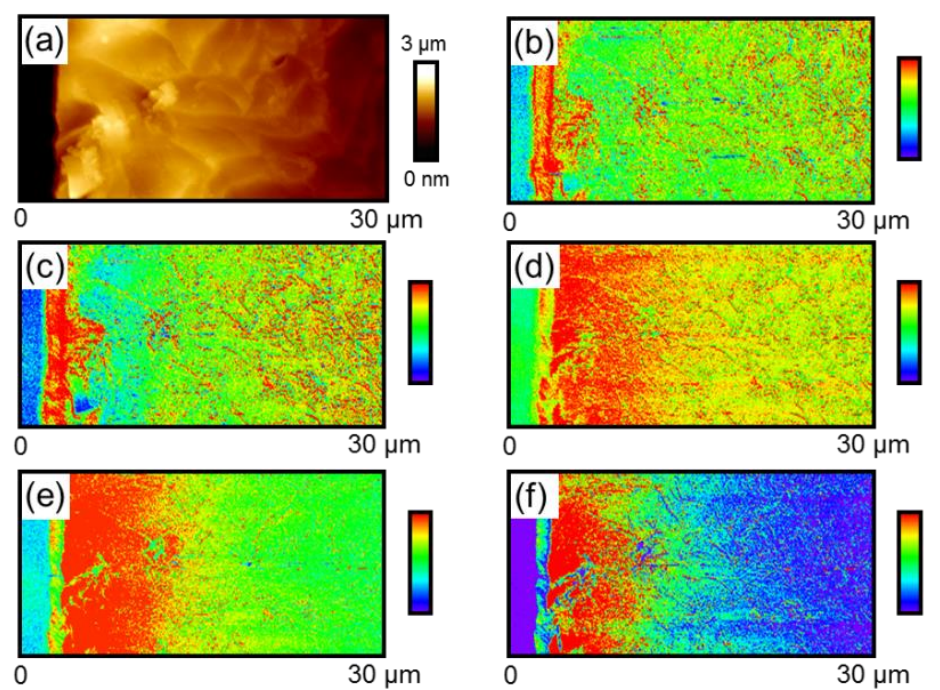

Figure 8. $30 \mu \mathrm{m} \times 15 \mu \mathrm{m}$ AFM-IR images of a microtomed cross-section of an epoxy resin from Sample B after 6000 minutes electrical stress: (a) contact mode height image, and ratio maps generated from infrared amplitude maps gathered at: (b) $1080 \mathrm{~cm}^{-1} / 1505 \mathrm{~cm}^{-1}$; (c) $1248 \mathrm{~cm}^{-1} / 1505 \mathrm{~cm}^{-1}$; (d) $1336 \mathrm{~cm}^{-1} / 1505 \mathrm{~cm}^{-1}$; (e) $1660 \mathrm{~cm}^{-1} / 1505 \mathrm{~cm}^{-1}$, and (f) $1752 \mathrm{~cm}^{-1} / 1505 \mathrm{~cm}^{-1}$. 


\section{Silicone Rubber ATR-FTIR}

In contrast to the epoxy specimens, surface tracks appearing on the silicone rubber surfaces were white in appearance, with no visible penetration into the bulk polymer. Furthermore, bulk ATR infrared spectra remained largely unchanged following electrical stress, Figure 9 and Table 2. This is in keeping with the previous studies of interfacial tracking on silicone rubbers, where degradation products primarily consisting of $\mathrm{SiO}_{2}$ and short chain silicones have been detected using mass spectroscopy. ${ }^{14}$ It has been proposed that these short chain species can readily migrate into the rubbery material. Ultimately, after prolonged electrical stress the formation of a broad carboxylic acid peak around $1674 \mathrm{~cm}^{-1}$ is detected, and this is accompanied by low levels of hydroxyl absorbance, indicative of oxidation.

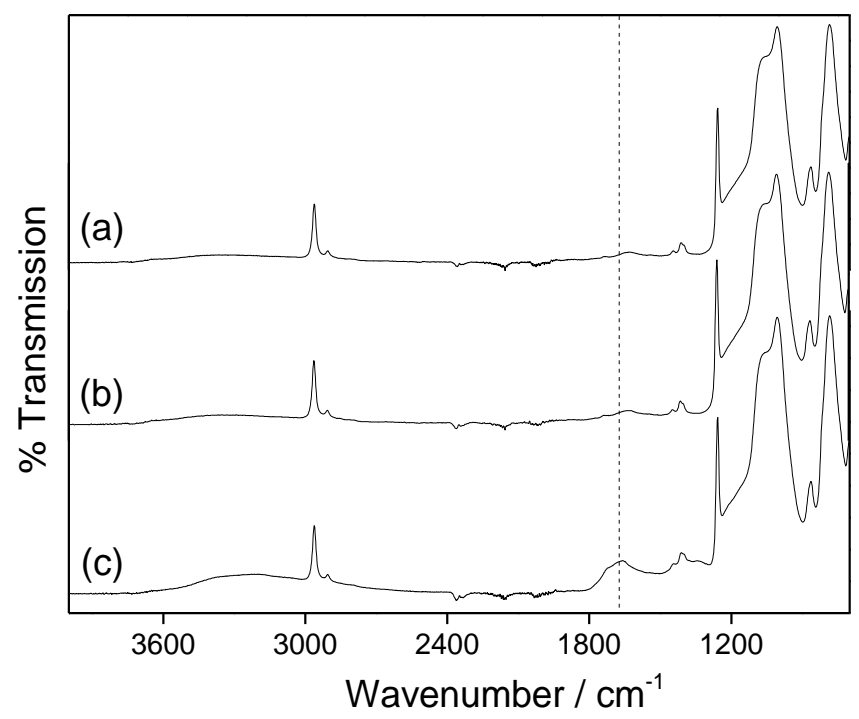

Figure 9. ATR mode FTIR spectra of silicone rubber part of samples collected (a) before the interfacial tracking experiment; (b) Sample A after exposure to partial discharge for 1020 min; (c) Sample B after exposure to partial discharge for $6000 \mathrm{~min}$. 


\section{Silicone Rubber AFM-IR}

Height images obtained on the silicone rubber part of sample B after 6000 minutes electrical stress showed that the surface tracks were less clearly defined than those found on the epoxy resin, Figure 10. This is consistent with previously reported partial recovery of channels formed in silicone rubber samples after electrical aging, ${ }^{37,38}$ attributed to the flexibility of silicone rubber and its local plasticization by short chain degradation products.

Table 2: Infrared spectroscopy peak assignments for silicone rubber samples.

\begin{tabular}{c|c}
\hline Wavenumber & Peak Assignment \\
\hline $788 \mathrm{~cm}^{-1}$ & $\begin{array}{c}\text { Si-CH } \mathrm{CH}_{3} \text { asym. rock + Si-C asym. } \\
\text { Stretch }\end{array}$ \\
$1009 \mathrm{~cm}^{-1}$ & Si-O-Si sym. Stretch \\
$1070 \mathrm{~cm}^{-1}$ & Si-O-Si asym. Rock \\
$1258 \mathrm{~cm}^{-1}$ & $\mathrm{Si}-\mathrm{CH}_{3}$ sym. Bend \\
$1412 \mathrm{~cm}^{-1}$ & $\mathrm{Si}-\mathrm{CH}_{3}$ asym. Bend \\
$1446 \mathrm{~cm}^{-1}$ & $\mathrm{CH}_{2}$ scissoring \\
$1674 \mathrm{~cm}^{-1}$ & Carboxylic acid C=O stretch \\
$2907 \mathrm{~cm}^{-1}$ & $\mathrm{CH}_{2}$ sym. Stretch \\
$2958 \mathrm{~cm}^{-1}$ & $\mathrm{CH}_{2}$ asym. Stretch \\
$3340 \mathrm{~cm}^{-1}$ & Hydroxyl O-H stretch \\
\end{tabular}

Nonetheless, local AFM-IR spectra were found to differ considerably from the bulk ATR-FTIR spectrum, indicating that substantial chemical changes occurred the interface. Using AFM-IR, it can be seen that Si-O-Si peaks at $1009 \mathrm{~cm}^{-1}$ and $1070 \mathrm{~cm}^{-1}$ are replaced across the interface by a broad absorbance at $1126 \mathrm{~cm}^{-1}$, corresponding to the formation of Si-O-C bonds. This can be attributed to the expected release of $\mathrm{SiO}_{2}$ and short chain silicone products. ${ }^{14}$ Further localised Si-O bond breakage was also indicated within the central track by the disappearance of this $1126 \mathrm{~cm}^{-1}$ peak, alongside increased absorbance at $1240 \mathrm{~cm}^{-1}$, indicating C-O-C bond formation occurred at a later stage of degradation. This is in keeping with a gradual carbonization process within the tracks, which may ultimately lead to the development of graphitic deposits, as has previously been reported for electrical treeing in silicone rubber. ${ }^{37}$ Finally, the spatial distribution of these species was also confirmed by infrared mapping, Figure 11. 


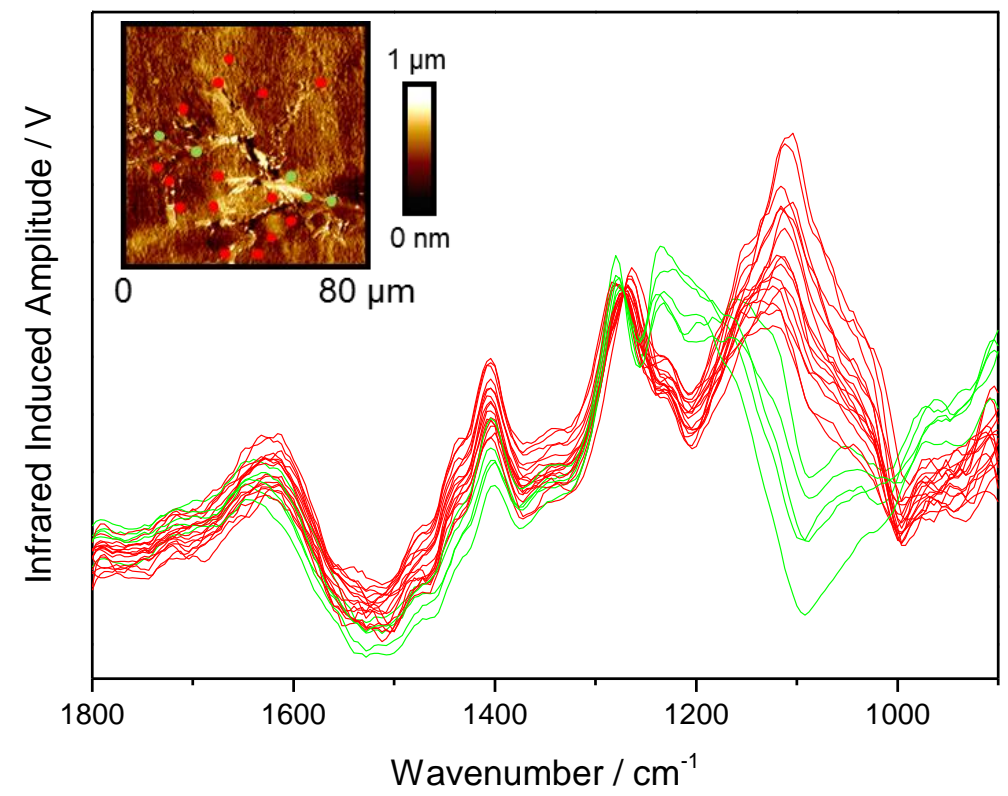

Figure 10. AFM-IR spectra corresponding to tip locations indicated by markers on the contact mode height image (inset) of the silicone rubber surface after 6000 minutes electrical aging (Sample B). AFM-IR spectra are normalised relative to the signal at $1258 \mathrm{~cm}^{-1}$.
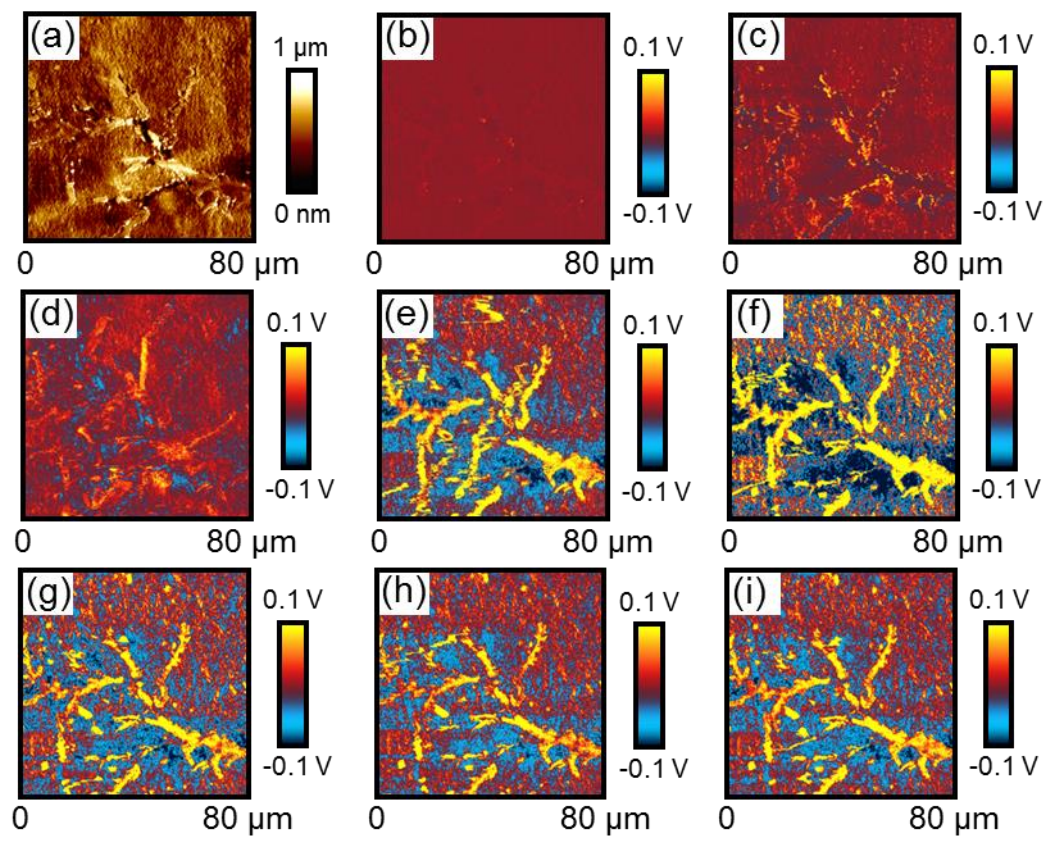

Figure 11. $80 \mu \mathrm{m} \times 80 \mu \mathrm{m}$ AFM-IR images of the silicone rubber surface from Sample B after $6000 \mathrm{~min}$ electrical aging: (a) contact mode height image and maps of the amplitude signal induced by pulsed infrared illumination at (b) $1048 \mathrm{~cm}^{-1}$; (c) $1126 \mathrm{~cm}^{-1}$; (d) $1156 \mathrm{~cm}^{-1}$; (e) $1240 \mathrm{~cm}^{-1}$; (f) $1276 \mathrm{~cm}^{-1}$; (g) $1404 \mathrm{~cm}^{-1}$; (h) 1440 $\mathrm{cm}^{-1}$, and (i) $1636 \mathrm{~cm}^{-1}$. 


\section{Conclusions}

AFM-IR has provided detailed, submicron resolution images of interfacial tracks and the associated chemical and physical damage inflicted by the early stages of partial discharge induced degradation at the interface between an epoxy resin and silicone rubber. For epoxy resins, comparison with bulk ATR-FTIR spectra has shown that the interfacial region is oxidised in a manner comparable to the degradation induced by partial discharge in air. The formation of $\mathrm{C}=\mathrm{C}, \mathrm{C}=\mathrm{O}, \mathrm{C}-\mathrm{O}$ and $\mathrm{N}-\mathrm{O}$ bonds was found to accompany dark track formation. Esters are formed at later stages in of degradation, preceded by alkene and hydroxyl intermediates, which are present at the periphery of channels. The degradation of the silicone rubber was less pronounced, where white channels were primarily formed as a result of Si-O bond cleavage.

\section{Conflicts of Interest}

There are no conflicts to declare.

\section{Acknowledgments}

S. Morsch is grateful to AkzoNobel for financial support and materials, specifically S. R. Gibbon for his guidance. P. Bastidas is thankful to EPSRC and The University of Manchester for a DTA grant in support of this project. 


\section{References}

1. G. H. Vaillancourt, S. Carignan and C. Jean, IEEE Trans. Power Deliv., 1998, 13, 661-666.

2. H. C. Kamer and M. leda, Proc. 3rd Int. Conf. Prop. Appl. Dielectr. Mater., 1991, 592-597.

3. A. Kutil and K. Froshlich, Annu. Rep. Conf. Electr. Insul. Dielectr. Phenom., 1995, 343-347.

4. M. Jarvid, A. Johansson, V. Englund, A. Lundin, S. Gubanski, C. Müller and M. R. Andersson, J. Mater. Chem. A, 2015, 3, 7273-7286.

5. H. Zhang, Y. Shang, H. Zhao, X. Wang, B. Han and Z. Li, RSC Adv., 2016, 6, 11618-11630.

6. Y. Wang, L. Wang, Q. Yuan, Y. Niu, J. Chen, Q. Wang and H. Wang, J. Mater. Chem. A, 2017, 5, 1084910855.

7. Y. Wang, J. Cui, L. Wang, Q. Yuan, Y. Niu, J. Chen, Q. Wang and H. Wang, J. Mater. Chem. A, 2017, 5, 47104718.

8. C. Nyamupangedengu and D. R. Cornish, IEEE Trans. Dielectr. Electr. Insul., 2016, 23, 85-94.

9. G. Bacquet, J. Dib, C. Y. Wu, M. R. Wertheimer, A. Yelon, J. R. Densley and S. A. Boggs, IEEE Trans. Electr. Insul, 1978, El-13, 157-163.

10. X. Chen, Y. Xu, X. Cao, S. J. Dodd and L. A. Dissado, IEEE Trans. Dielectr. Electr. Insul., 2011, 18, 847-860.

11. A. S. Vaughan, I. L. Hosier, S. J. Dodd and S. J. Sutton, J. Phys. D: Appl. Phys., 2006, 39, 962-978.

12. E. L. Leguenza, R. Robert and J. a. Giacometti, IEEE Trans. Dielectr. Electr. Insul., 2004, 11, 406-417.

13. S. Rasikawan, H. Ishihara and N. Shimizu, IEEE Trans. Dielectr. Electr. Insul., 1994, 1, 597-603.

14. D. A. Bolliger and S. A. Boggs, IEEE Trans. Dielectr. Electr. Insul., 2012, 19, 996-1006.

15. L. Hu, Y. Xu, X. Huo and Y. Liao, IEEE Trans. Dielectr. Electr. Insul., 2016, 23, 738-747.

16. A. Dazzi and C. B. Prater, Chem. Rev., 2017, 117, 5146-5173.

17. C. Marcott, M. Lo, E. Dillon, K. Kjoller and C. Prater, Microsc. Today, 2015, 23, 38-45.

18. S. Morsch, S. Lyon, S. D. Smith and S. R. Gibbon, Prog. Org. Coat., 2015, 86, 173-180.

19. S. Morsch, S. Lyon, P. Greensmith, S. D. Smith and S. R. Gibbon, Faraday Discuss., 2015, 180, 527-542.

20. S. Morsch, Y. Liu, S. B. Lyon and S. R. Gibbon, ACS Appl. Mater. Interfaces, 2016, 8, 959-966.

21. B. Lahiri, G. Holland and A. Centrone, Small, 2013, 9, 439-445.

22. S. Morsch, B. A. Van Driel, K. J. Van Den Berg and J. Dik, ACS Appl. Mater. Interfaces, 2017, 9, 1016910179.

23. D. Khanal, A. Kondyurin, H. Hau, J. C. Knowles, O. Levinson, I. Ramzan, D. Fu, C. Marcott and W. Chrzanowski, Anal. Chem., 2016, 88, 7530-7538.

24. J. R. Felts, K. Kjoller, M. Lo, C. B. Prater and W. P. King, ACS Nano, 2012, 6, 8015-8021.

25. F. Tang, P. Bao and Z. Su, Anal. Chem., 2016, 88, 4926-4930.

26. P. D. Bastidas and S. M. Rowland, IEEE Electr. Insul. Conf., 2017, 13-16.

27. Y. Ngono and Y. Maréchal, J. Polym. Sci., Part B: Polym. Phys., 2000, 39, 329-340.

28. D. Lin-Vien, N. B. Colthup, W. G. Fateley and J. G. Grasselli, The Handbook of Infrared and Raman Characteristic Frequencies of Organic Molecules, Academic Press Ltd, London, 1991.

29. S. P. Nunes, R. A. da Costa, S. P. Barbosa, G. R. Almeida and F. Galembeck, IEEE Trans. Electr. Insul., 1989, 24, 99-105.

30. V. Ollier-Dureault and B. Gosse, J. Appl. Polym. Sci., 1998, 70, 1221-1237. 
31. A. Garton, IEEE Trans. Electr. Insul., 1980, 15, 500-501.

32. D. M. Hepburn, I. J. Kemp, A. J. Shields and J. Cooper, IEE Proc. - Sci. Meas. Technol., 2000, 147, 97-104.

33. S. Cotugno, D. Larobina, G. Mensitieri, P. Musto and G. Ragosta, Polymer, 2001, 42, 6431-6438.

34. M. M. Shahin, J. Chem. Phys., 1966, 45, 2600-2605.

35. M. M. Shahin, Appl. Opt., 1969, 8 Suppl 1, 106-110.

36. Y. Toriyama, H. Okamoto, M. Kanazashi and K. Horii, IEEE Trans. Electr. Insul, 1967, E1-2, 83-92.

37. Y. Zhang, Y. Zhou, R. Liu, X. Zhang, M. Wang and L. Zhang, J. Electrost., 2015, 76, 83-88.

38. Y. Zhou, R. Liu, F. Hou, X. Zhang and W. Xue, J. Electrost., 2013, 71, 440-448. 